\title{
LA MIRADA VOYEUR: CONSTRUCCIÓN Y FENOMENOLOGÍA
}

\author{
THE VOYEUR GLANCE: \\ CONSTRUCTION AND PHENOMENOLOGY
}

\section{Carolina Sanabria*}

RESUMEN

Este artículo pretende establecer un estudio en torno a la problemática de la visión en el seno de los estudios culturales. Se trabaja con una de las visiones proscritas, la voyeur, que está a la base de la génesis del aparato cinematográfico y los géneros de ficción que de ahí derivan (básicamente a partir del canon clásico —y tácito- de la no correspondencia de la mirada del actor con el eje de la cámara) pero cuya complejización posiciona al espectador como tal, sobre todo en los programas televisivos típicos de la neotelevisión (realities).

PALABRAS CLAVE: TEORÍA DE LA COMUNICACIÓN * PSICOANÁLISIS * CINE * ARTES VISUALES * ARTES DEL ESPECTÁCULO * PERSONAJE * VOYEUR

\section{ABSTRACT}

That article tries to find a view around the problematic of vision in the cultural studies. It deals with the prohibited voyeur vision, which is in the basic origins of the cinematographic and fictional works. In addition, the article approaches the absence of glance of the actor to the camera which in turn tends to get complex for different audiences mainly, in the typical televising programs of the neotelevision. A good example of this neo-tv is the reality shows.

KEY WORDS: THEORY OF THE COMMUNICATION * PSYCHOANALYSIS * CINEMA * VISUAL ARTS * ARTS OF THE SPECTACLE *CHARACTER * VOYEUR

Nada hay más natural para la especie humana o incluso más indispensable para la supervivencia primitiva o animal que el mirar, pero, con el desarrollo y la complejización de la mirada - a partir sobre todo del impulso de los medios de masa-, la cultura condena este

Cátedra de Comunicación y Lenguaje, Escuela de Estudios Generales, Universidad de Costa Rica. acto en ciertas circunstancias y/o ciertas intensidades, como las que involucran el largamente debatido sentido de la visión sobre el cuerpo. Son formas en las que sus imágenes -asumidas como reales $y$ vivas - tienen la propiedad de despertar el deseo del espectador: "al percibir el 
cuerpo como algo real y vivo, somos capaces de desearlo", dice Freedberg (1992: 367). Esta relación entre la mirada con la curiosidad $y / 0$ el deseo está a la base de la prohibición de las imágenes - por eso el contacto visual instaura un tabú, como se constata en muchas culturas que desaprueban la mirada fija en tanto revela un exceso de intimidad, de sexo o de expresión demasiado libre de las emociones (Davis, 1973: 85)—1.

A partir de esta problematización entre la mirada y la representación del cuerpo en la cultura se formaliza un tabú donde se inscriben una serie de formas de estigmatización de la mirada, que se han distinguido en categorías como el narcisismo, la representación pornográfica y la visualización del cadáver - que desembocan en dos eventos alusivos a la condición humana los cuales muchas veces suelen obviarse, en buena parte por sus connotaciones de animalidad (la sexualidad) o de precariedad (la muerte) - . Hay un cuarto tipo de visión (y fruición), referido a cuando se ejerce de manera subrepticia sobre actividades íntimas de otros sujetos, que básicamente es la definición del Diccionario de la Real Academia de la Lengua Española (DRAE) en su última edición (2001). A partir de aquí se plantea, en primera instancia, que una de las expresiones más condenables de la mirada - considerada incluso patológicaha sido asumida en la sociedad contemporánea por los medios de masa.

La mediatización social favorece la manifestación de este prototipo de mirada, aunque no constituye un fenómeno típicamente exclusivo de la contemporaneidad - como permite constatar la pintura del Quattrocento en manifestaciones aisladas que se remontan a la figura del mirón como pretexto - uno de los más paradigmáticos, Susana y los viejos, hacia 1550, de Tintoretto (Fig. 1) - o, lo que es lo mismo, como mecanismo de exoneración moral

1 En este sentido, Hall se preguntaba "why 'the look' is so powerfully inscribed by the play of desire, so that no look is ever satisfying, but always excites the drive to look more, to see beyond, as if to gaze enough would be to see what is forbidden, what should not be shown or seen" (en Evans and Hall, 2003: 313). del creador-. El cuadro en cuestión ilustra cabalmente este tipo de mirada, en el que aquellos, ocultos en la espesura del bosque, atisban las blancas formas de la muchacha ocupada en su acicalamiento - al tiempo que incluye otra relacionada con el placer (y la prohibición): la narcisista, Susana misma mirándose al espejo-. Tampoco es un fenómeno exclusivo del género audiovisual — pues en menor medida, hay prácticas literarias (escasas, eso sí) que también lo abordan como eje central, entre las que es preciso mencionar El mirón (Le voyeur, 1955) de Alain Robbe-Grillet y El hombre que mira (L'uomo che guarda, 1985) de Alberto Moravia-. Sin embargo, la cuestión voyeur tiene especial propensión para ser tematizada y problematizada en el discurso fílmico, posiblemente porque la mirada es lo que más ampliamente está a la base de los media — de donde Clay Calvert se sirve para proponer su teoría de voyeurismo mediado (2004)—.

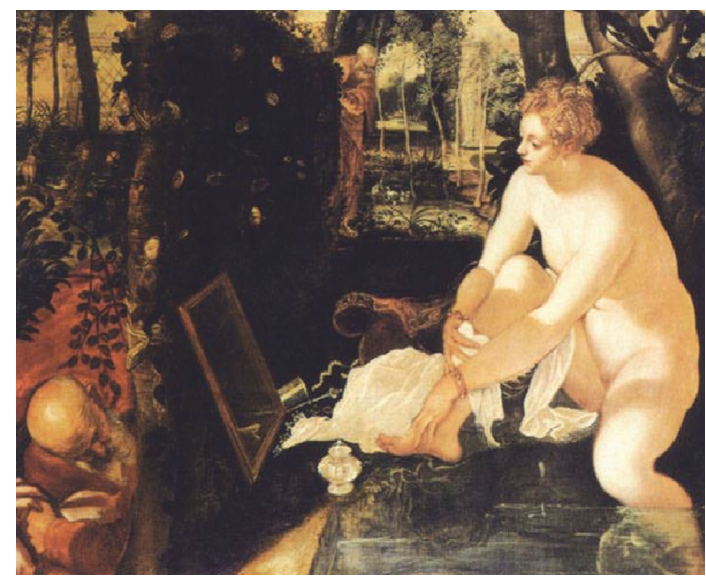

Fig. 1. Jacopo Tintoretto. Susana y los viejos (hacia 1550).

La difusión que presupone la incorporación del voyeurismo a los medios de masas estimula su producción y contribuye a su cotidianización. Se potencia con la fotografía y el cine, aunque también, desde mediados del siglo $\mathrm{xx}$, fue recuperado en la plástica, como lo evidenció esencialmente Marcel Duchamp en la exposición de los dispositivos de la mirada oculta de su inacabada instalación Étant donnés: $1^{\circ}$ la chute d'eau, $2^{\circ}$ le gaz d'éclairage (1946-1966). 
En este proyecto monumental el entorno del museo y la sala en especial se confabulan para llevar al espectador a situarse - literalmenteen la posición de un voyeur, a exponerse ante la mirada del otro al igual que el desnudo femenino que se descubre tras el agujero. La instalación se desempeña como un cepo que prende al espectador y que ilustra la metáfora del voyeur mirado de Sartre: la escena deja en evidencia la pulsión - constituida en una abyección reprimida - que lo gobierna. Asimismo lo reconfirmaba el autor en una entrevista realizada un par de años antes de su defunción, en la que declararía que "son los mirones [regardeurs] los que hacen los cuadros" (Ramírez, 2000: 247). Por tanto, no sólo la mirada construye al objeto: también la imagen puede construir miradas — esto es, al espectador como voyeur-.

Esta posición del espectador como voyeur se inserta en un nuevo régimen de representación visual: todo es susceptible de convertirse en objeto de una mirada. Hay, incluso, imágenes que, singularizándose de su entorno, adquieren la capacidad de convertirse en un vehemente reclamo a la mirada, como es el caso, en la cinematografía, de los pies de Gloria en $E l$ (1952) de Luis Buñuel. Aun sin recurrir a un escondite más o menos formal, se puede decir, tomando en consideración el entorno piadoso donde la imprevista visión tiene lugar, que estos llegan a apelar a la mirada - voyeur, naturalmente - del protagonista Francisco de Montemayor - es, sin lugar a dudas, una mirada subrepticia, al sesgo, que llama Žižek (2002) - y hasta suscitar brazales fetichistas.

Llegados a este punto, hay que precisar la emergencia de una tercera instancia a la polaridad freudiana de mirar-ser mirado que merece una breve digresión. Mucho se ha hablado, desde Freud, de que el voyeurismo se complementa con la exhibición (1973a), lo cual ha derivado en teorizaciones como la reelaborada por el novelista Moravia - suscrita a su vez por Jean Starobinski² — de que "a cada voyeur

Quien también llega a una deducción semejante: "el exhibicionismo y el voyeurismo forman una pareja de tendencias a la vez opuestas y complementarias, [con lo que] todo exhibicionista es también, a ratos, mirón” (Starobinski, 2002: 105). corresponde su exhibicionista y viceversa" (2002: 60). Sin embargo, es un planteamiento refutable en tanto la exhibición desarticula al voyeur, que ante todo se define como mirada furtiva donde el otro no es consciente de ser mirado. La correspondencia se inscribe, como lo reconocía Román Gubern, en una desactivación de placeres no sólo en el caso del voyeur, sino también en la puesta en escena del exhibicionista ${ }^{3}$.

La mencionada dicotomía se desestructura además a través de un argumento que apunta a lo que se mencionaba con anterioridad. No sólo habría algo que es objeto de la mirada (voyeur) y algo que tiene la voluntad de ofrecerse (exhibición): habría también un grado o tipo de imagen donde esta tiene la particularidad de demandar una mirada intensa, lo cual dota al objeto observado de una nueva valoración. Además del mencionado caso de los pies de Gloria, hay un ejemplo muy claro en la premiada película del cineasta austriaco Michael Haneke, Escondido (Caché, 2005). El filme abre con un plano general del exterior de una casa tomada por una cámara fija cuyo registro contiene un doble estatuto de la imagen para el espectador: se trata de una sola mirada - despejada, abierta - que adquiere en sí misma otras significaciones en el momento en que se descubre que en realidad está vista desde una situación anómala, subrepticia, la de un anonimato revestido de destilaciones que rozan lo siniestro y la desfamiliarización que conlleva el envío metódico de ese tipo de material.

Recuperando, pues, lo comentado anteriormente - la conversión de imágenes en objetos para la mirada-, es preciso acotar que la sociedad audiovisual generaliza la tendencia de la transformación de los objetos en imágenes muchas veces de tipo voyeur. En cualquier caso, se está ante un nuevo régimen de

De acuerdo con Gubern, Freud había planteado la correspondencia entre el sadismo (lo activo) con su contraparte, el masoquismo (lo pasivo), la cual posteriormente es disentido por Lacan y Deleuze, quienes no veían concomitancia alguna entre ambas conductas y consideraban que la manifestación del placer de la víctima desactivaba el placer sádico (2002: 189). 
representación visual, ante una idea del cuerpo construido para la mirada del otro, como han trabajado fundamentalmente los estudios del género con la cineasta $y$ teórica inglesa Laura Mulvey a la cabeza en su célebre ensayo de 1973 donde planteaba a la mujer como espectáculo de la mirada, una línea muy generalizada en el cine industrial y en el resto de la producción sometida a las reglas de la mercantilidad. Sin negar la validez de la propuesta de Mulvey, habría que ampliar esta concepción de la mirada focalizada en el otro, puesto que, como desarrolla Josep M. Català, la fenomenología de la percepción es multiestable más que objetivadora e incluye miradas del cuerpo del otro superpuestas a las del propio, produciéndose lo que llama una escisión de la conciencia del cuerpo a través de una mirada híbrida. Dicho de otro modo, se trata de una percepción dual que se compone tanto de la percepción del otro como la percepción interna del propio cuerpo (2002: 60$)^{4}$. Esta dualidad se extrapola a la base del lenguaje cinematográfico, puesto que funciona mediante la combinación o alternancia entre básicamente planos subjetivos $y$ planos objetivos.

Sin negar el componente connatural de la visión, muchas veces inconsciente pero en definitiva siempre pulsional, la estructura voyeur evidencia su presencia en el lenguaje fílmico como lo que se ha identificado en tres ámbitos

A raíz del referido texto de Idhe, Català propone una mirada híbrida que no excluye la percepción que tiene el sujeto de sí mismo: "Les mirades no són mai simplement d'un sol gènere, sinó que inclouen mirades masculines i mirades femenines sobreposades: per exemple, la percepció que una dona té de si mateixa inclou la seva automirada i la presumible mirada masculina corresponent, un fenomen que s'estén també més ellà de l'autopercepció cap a la percepció de l'altre i del món" (2002: 60). Esto es particularmente claro en géneros como los videojuegos, donde la mirada sobre el otro contribuye a la construcción de la propia imagen del espectador - al modo de un reflejo narcisista - en el que el jugador (varón) puede subrogarse en un personaje (femenino) o viceversa, así como otro medio análogo, internet, cuyas páginas de conversación (chats) se prestan para que sus usuarios muchas veces asuman $-y$ esta vez deliberadamente- otras posibilidades de género y de orientación sexual. que se asumen en el consumo de productos de ocio, tradicionalmente de ficción: el de la perspectiva, el de la recepción y el de los contenidos.

\section{DE LA PERSPECTIVA}

Las convenciones fílmicas han hecho equivaler la mirada voyeur a la perspectiva subjetiva porque se suele emparejar este tipo de mirada con la de un personaje, como si la omnisciente, normalmente equiparada a la divina, se lograra eximir de impulsos atribuidos a lo que se antoja una vergonzosa humanidad, además de que cualquier encuadre, cualquier angulación, cualquier movimiento de cámara supone siempre la presencia anterior de una entidad invisible que dispone previamente las cosas, que las somete a un proceso de escogencia y organización, esto es, de artificialización.

De ahí la relevancia de la producción de Michael Haneke, que demuestra con claridad que la mirada voyeur está lejos de agotarse en la perspectiva subjetiva. Es un cineasta que ha producido renovadoras experimentaciones visuales que trascienden tal uso de la perspectiva voyeur limitada a la subjetiva. Probablemente una de las mejores demostraciones fílmicas de este atributo en la conciencia del espectador lo haya plasmado en sus excepcionales planos de espacios en off o fuera de campo a partir de una cámara fija. Por ejemplo, en Código desconocido (Code inconnu, 2001), el espectador queda posicionado como un voyeur-voyageur que transita por varios escenarios culturales desde una posición más o menos oculta. Desde una cámara cuya visión está claramente entorpecida, al espectador de Haneke se le niega cualquier posibilidad de acceder a una imagen totalizante: no está en condición de observar lo que quisiera y como quisiera - o como ha sido acostumbrado, con la visualidad extrema de hoy que no deja el menor resquicio sin escrutar, ante una visión privilegiada que resulta más real que la realidad y cuyos cánones de representación describen prolija y plenamente hasta derivar en esa estética de plena actualidad en que se inscribe la visualidad total que Calabrese (1989) denominaba de fragmentación y detalle (propia, por cierto, de la posmodernidad en géneros que 
abarcan desde las transmisiones deportivas hasta la producción pornográfica)-. En la producción de Haneke, el espectador, entonces, pierde el punto central y privilegiado desde el que tradicionalmente se ha organizado la escena visual, pues deja de tener acceso a ciertos detalles (los derivados de Eros y Thanatos) en lo que acontece sobre el cuerpo y, en contraparti$\mathrm{da}$, a las emociones reflejadas en la fisionomía de los personajes -en Código desconocido, por ejemplo, abundan contraplanos en los diálogos desde planos cerrados, pues están tomados desde una cámara fija que hasta podría resultar exasperante- Tampoco - a excepción básicamente de los plano-secuencia de los que también se compone el filme- el espectador está en posición de dar siempre un seguimiento detallado a las acciones de aquellos, pues en su calidad de expectación está impedido por barreras que nacen una inmovilidad de la que ya había dado cuenta Hitchcock y que en cierto modo había sido empleado en otro texto de otro género - esta vez literario-El mirón de Robbe-Grillet, donde la figura del voyeur, aquí traslapada al lector, queda excluida de la visión, puesto que la pormenorización en extremo puntual, casi matemática, de un itinerario en torno a un suceso que integra sexualidad $y$ muerte y que al mismo tiempo constituye el clímax de la novela, resulta omitido en forma íntegra, con lo que inevitablemente el voyeur resulta defraudado.

\section{DE LA RECEPCIÓN}

Dentro de los elementos que evidencian la estructura voyeur en el aparato fílmico, cabe destacar que la logística también se suma a crear una atmósfera voyeur, aunque ya de por sí el cine, por sí mismo, proporciona al espectador "la ilusión de mirar a un mundo privado" (Mulvey, 1988: 6) que nunca se sacia — porque como recupera Doane, "[h]ay mucho que ver" (en Screen, 1999: 231) —. La naturaleza visual del espectador está atravesada por la voracidad: nunca se satisface de acceder a una realidad extraña sobre una circunstancia y unos personajes igualmente extraños a él. Pero además, ya desde las disposiciones físicas del medio, las salas - con sus condiciones vinculadas implícitamente con la clandestinidad (como la oscuridad, el silencio, la inmovilidad que favorecen el anonimato y el aislamiento de los concurrentes) para centrar su actividad exclusiva en el ejercicio de la mirada- se favorece una regresión al estadio oral del sujeto - el silencio y la oscuridad de la sala, la inhibición motriz, su pasividad ante el flujo de imágenes (Aumont et ál., 1996: 260)—.

\section{DE LOS CONTENIDOS}

Son los elementos de carácter voyeurista más evidentes. Tienen que ver con la construcción del contenido en lo referente a la filmografía, que ya desde su base contiene la convención tácita de que la mirada de sus intérpretes no ha de coincidir nunca con la del lente de la cámara. Tal particularidad no en vano estuvo presente en los orígenes de la fotografía: sus primeros ensayos, en el caso de algunos de sus pioneros (Talbot, Daguerre y Bayard), trabajaron con imágenes subrepticias de ciudadanos en circunstancias que inadvertían, así como de sujetos que no posaban (o, nunca se sabrá, que posaban como si no posaran, exactamente como tal y como trabajan los actores y figurantes de cine). Es decir, la cinematografía asienta sus fundamentos narrativos en el no reconocimiento de la presencia del espectador, posicionándolo en la expectación furtiva, es decir, como voyeur $-y$ la neotelevisión, como se verá más adelante, desarrolla productos en los que se acentúa aun más tal posicionamiento-.

Por tanto, sobresale que el voyeur sea una figura que en la narrativa fílmica delinea una marcada tipología de personajes ávidos de mirar - aun cuando sea (o mejor si se trata) de la contemplación de terceros en intimidad, no necesariamente de índole sexual (en lo cual aprovecho para recalcar que lo que se conoce como representación pornográfica está situado a las antípodas de la mirada voyeur: aun cuando sean dos tipos de representaciones que giran sobre el cuerpo, en esta última no hay lugar para el secreto, por el contrario, si algo caracteriza a la imagen pornográfica es la mostración total)-. Hitchcock, quizás el director más 
preclaro en el tratamiento de las psicopatías sexuales contemporáneas, es pródigo en la inclusión de personajes con mayor o menor grado de perturbación pero siempre dominados por una atracción óptica que está indisolublemente ligada a un desarrollo complejo de su psique: Scottie (Fig. 2), Jefferies, Bates... constituyen el paradigma del voyeur que ha derivado en el personaje solitario, incomprendido, asocial, obsesivo, introvertido, a veces edípico que, en algún momento, otros directores - Buñuel, Antonioni, Kieślowski, Powell, Leconte, entre otros - han problematizado desde diferentes inquietudes, ópticas y resultados. No obstante, por contrapartida, la indiscreción y oscura pulsión de las sombrías criaturas de estos demiurgos también se canaliza hacia lo políticamente correcto, sobre todo en las producciones mainstream: prototipos como el detective/ policía/fotógrafo/periodista reproducen con creces esta pulsión (Denzin, 1995) desde una pasmosa frivolidad en no pocos filmes y sobre todo en las series televisivas más inanes ${ }^{5}$.

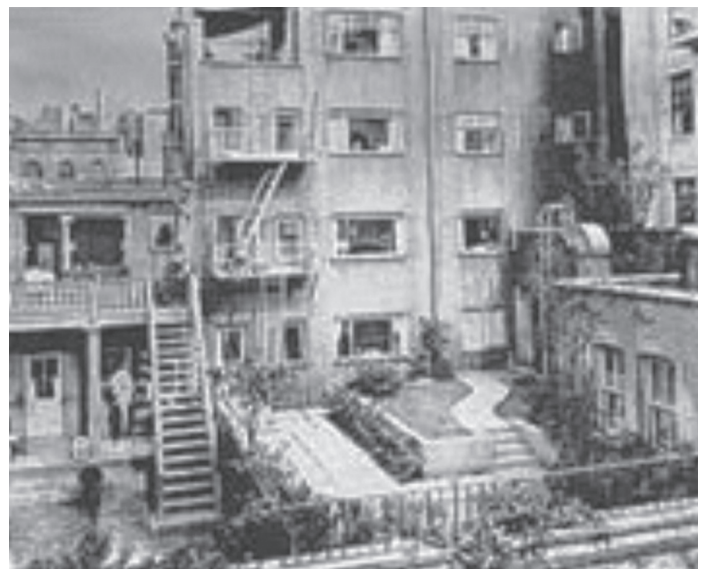

Fig. 2. El panóptico personal de Jeff, (Alfred Hitchcock, Rear Window, 1954).

De hecho, en algunas producciones del cine anterior al período que Denzin denomina - con base en la feliz distinción de Jameson- modernista tardío, suele aparecer delineado como un sujeto abstraído, con tendencia a la inadaptación, más o menos perturbado y en ocasiones hasta violento - Norman Bates es el paradigma-, cuya conducta se desborda en abusos que amenazan la esfera privada de la vida social y que apuntan al aislamiento, como reclama, tras descubrir que alguien asesinó
De todo lo anterior se desprende que el voyeur vendría a moverse entre dos espacios discordantes: la utopía de lo que pretende alcanzar su mirada, esto es, una visibilización prácticamente total (al estilo de la novela de Orwell, Nineteen-Eighty-Four (1948), donde la mirada de las cámaras sin fuera de campo, esto es, la capacidad ubicua de registro de imágenes en la diégesis sea uno de los elementos más ficcionales $-y$ probablemente el más inadvertido- de todos los que componen esa sociedad futurista). En tal visibilización extrema, la aproximación con lo mirado se reduce al grado cero, casi hasta alcanzarse la condición absoluta de la visión como un tacto a distancia. Pero al mismo tiempo hay un choque con sus posibilidades reales, prácticas - la posesión como una ilusión visual destinada a no cumplirse nunca-. En otras palabras, el voyeur se mueve entre la voluntad de visión que realiza idealmente su deseo $y$ las dificultades materiales, palpables que se interponen literalmente en su camino ( $y$ que se han intentado trasladar al lenguaje fílmico con la llamada perspectiva subjetiva) porque en eso reside su posición: en un desplazamiento de la perspectiva renacentista que se ha sustentado la cultura mediática, salvo casos excepcionales como el de Haneke.

En este deseo de visualidad total se inscriben las mal llamadas cámaras de seguridad (porque, como lo ha demostrado con creces la práctica, no constituyen una garantía de protección individual), aunque han supuesto una modificación de la forma de percepción de un entorno que se amplía al cotidiano. Son medios que suscitan, a la hora de documentar la realidad, una nueva forma de comunicación considerada más veraz que la escritura (partiendo 
de la falacia de la equivalencia o igualdad entre verdad e imagen, obviamente figurativa). No por estar ubicadas en zonas visibles, estas cámaras suponen la pérdida total del carácter voyeur del eventual espectador, si es que llega a haberlo. La ficción ha elucubrado con la posibilidad - que muchas veces se piensa lejana- de ocasionales empleos secundarios que pueden derivar en la delectación o bien trascenderla. Quizá una de las mejores ilustraciones de esto último haya sido plasmada recientemente por - de nuevo- Michael Haneke en Caché, donde a la familia del protagonista Georges Laurent se le hacen llegar videos de su entorno cotidiano en forma anónima: de hecho, inicia con un plano fijo de la fachada doméstica que pasa luego a adquirir un carácter perturbador. Al filme de Haneke no le interesa esclarecer, ni siquiera en su desenlace, quién los produce y/o envía, ni tampoco ahondar en las motivaciones para hacerlo. Sus preocupaciones - como ya se habló de ello- se centran en el tratamiento de la realidad a partir del cambio de significación dentro de la imagen misma ${ }^{6}$.

Además Caché parte de la constatación de que las imágenes más espectaculares e impactantes que difunden los medios, sobre todo las ligadas a la catástrofe (las paradigmáticas corresponden a las de los aviones que se estrellaron en las torres de Nueva York), incitan a la difuminación de los límites entre fantasía y realidad —en una dirección muy semejante al planteamiento de Yutaka Tsuchiya en Peep TV Show (2003) cuyo protagonista enuncia repetidas veces un discurso sobre unas imágenes también repetidas hasta la saciedad-, pues no tienen nada que ver con las tomadas por particulares, desarrolladas en ambientes familiares, de carácter más plácido y contemplativo. Marc Augé decía a ese respecto que en las pantallas

Como ya lo había hecho anteriormente en los primeros segundos de Funny Games (1997) pero en aquella ocasión desde la dimensión del audio: una doblez intencionadamente engañosa abocada a confundir ex profeso al espectador, pues lo lleva a dudar de la veracidad de lo que percibe a través de los medios. del planeta se mezclan las imágenes de la información, las de la publicidad y las de la ficción, cuyo tratamiento y finalidad no son en principio idénticas pero que componen bajo nuestros ojos un universo relativamente homogéneo en su diversidad (2000: 38). A Haneke le interesa dejar constancia de la existencia y diferencia entre ambos paradigmas de imaginarios a partir de, como lo indica el mismo título, lo oculto, aquí referido al protagonista y la transformación de la culpa de un hecho de la infancia en calculada indiferencia recubierta de erudición. No en vano es una culpa reducida a un simulacro (el decorado del plató de televisión del programa que el protagonista dirige) como parte de un mecanismo de autodefensa personal pero al mismo tiempo extrapolable a las sociedades industrializadas que se asientan (se enriquecen) en esa parte del mundo olvidada, rechazada, escondida - aun dentro de sus mismos márgenes (los suburbios parisinos) - y que pese a ello constituyen una fuerza importante de producción (la comunidad descendiente de la inmigración). Por eso en el plano inicial de la película pero sobre todo en el siguiente - la casa de la infancia de Georges Laurent- la imagen adquiere la condición, como diría DidiHuberman, de ineluctable (1997) porque la sostiene una pérdida y en calidad de tal, no sólo es un objeto mirado: ella misma (la casa) lo mira, lo asedia, lo persigue, lo atormenta.

Haneke trabaja, como los directores destacados (Weir, Tavernier, Howard), con la representación de la realidad en el impacto de la televisión. Los contenidos de los nuevos programas parten del referido manejo de las cámaras de videovigilancia para replantear un tipo de mirada que con estrechas aproximaciones a la voyeur. De hecho, con la rentabilidad y abaratamiento de costes de producción que caracteriza a los nuevos productos de la neotelevisión (Eco), hay una proliferación de estos nuevos espacios. De ellos se derivan dos tipos básicamente a partir del manejo de cámara (de la visión del espectador): la oculta (candid camera) y la expuesta (el Gran Hermano y sus spin-offs). El último tipo, de especial acogida en años postreros, parte de lo que Freud reconocía como un pueril impulso de exhibición 
(1973a) en una nueva categoría de sujetos ya no limitados a una dedicación del oficio de stars. A ese respecto, John Langer llegó a formalizar una distinción a partir de lo que denominó los actores destacados: por un lado, las habituales celebridades que por sí mismas llegan a generar un considerable nivel de interés - con historias que tienden a construirse alrededor de sus rutinas$y$, por otro, la progresiva inclusión de la gente común (no destacable) - a la que se le cede espacio por su capacidad de realizar, inversamente, acciones extraordinarias a partir de la materia prima de su entorno inmediato- (2000: 72-74). Estos sujetos admiten (ansían) ingresar en circuitos sembrados de cámaras y micrófonos, lo que constituye una actualización de ese concepto dieciochesco conocido como el panóptico de Bentham $(1985)^{7}$. El tipo de filmación que desde ahí se articula, sin duda, tiene que ver con el mencionado ideal de visibilidad total, que por lo demás ha modificado la normalidad escópica que dirigía los visionados habituales.

Este tipo de espacios, cuyos formatos son conocidos como telerrealidad, explotan la pulsión connatural del espectador para simular una situación de furtividad en la circunstancia expectatorial de situaciones vendidas como reales -en los que la ficción se desplaza en principio hacia un componente de verdad que podría descubrirse como intensificador de la mirada voyeur-. Pero se instaura una nueva modalidad de espectáculo basada en el como si: dada la alta carga de estigmatización con que está teñido este tipo de productos, el que mira adopta ante los demás y casi ante sí mismo la

El diseño de Bentham constaba de un conjunto de celdas organizadas semicircularmente (intermediatelannular area) en torno a una torre que se levantaba en el centro (inspector's lodge). Cada celda estaba dispuesta con dos ventanas, una de las cuales daba hacia el exterior del edificio y otra al interior - de cara a la torre de vigilancia-. Punto central y elevado - cercano a dios-, esta torre era un reducto que funcionaba como un módulo de inspección que confería acceso a la visualidad absoluta de cada uno de los cuerpos ahí registrados e incomunicados - de la misma manera que el director de las salinas, en el proyecto de Ledoux, custodiaba las actividades de sus trabajadores-. actitud de como si no mirara, y el que es mirado actúa como si no fuese mirado. Se trata de programas - cuyo desarrollo demuestra por cierto que resultan mal llamados de convivencia- donde la exhibición está estrechamente vinculada con la artificialización en grados variables e indeterminables pero inevitablemente crecientes, como dan cuenta las (hasta donde las posibilidades lo permiten) variadas ediciones del espacio fundacional - Gran Hermanocuyo logo daba cuenta, ya por sí mismo, de la dirección del programa: la vigilancia. Si, por un lado, vienen a dar cuenta de que el voyeurismo no puede limitarse a la ficción, el hecho de que recurran con mayor atrevimiento a una elaboración cada vez más artificiosa (en la elección de sujetos mayormente espectaculares, en la propia construcción narrativa de los resúmenes, en la asignación, por parte de los programas paralelos, de algunos roles que recuerdan los del paradigma greimassiano...) quizá se explique porque al final de cuentas lo que se ha conocido - o mejor, lo que se ha construidocomo realidad no siempre resulta lo suficientemente atrayente por sí sola.

Todo este impulso televisivo del voyeurismo ha de verse inmerso dentro de la activación de una progresiva demanda de participación del espectador. Es parte de un deseo que tiene antecedentes propios del inconsciente por integrarse a la escena y que había sido particularmente evidenciado por Hitchcock en La ventana indiscreta (Rear Window, 1954), donde el personaje femenino, Lisa Freemont, se animaba a intervenir como instrumento de mediación entre la voluntad y la acción de su indispuesto novio, a la manera de una operación de subrogación. Por cierto que una traslación burda y mercantil pero alineada con esa inconfesada ambición del espectador que intenta llevar a cabo una participación cada vez mayor se reproduce con las llamadas telefónicas en Gran Hermano y sus spin-off que resultan concursos de inconvivencia. A principios de 2006, la cadena generalista española Tele5 lanzó un nuevo programa (fugaz, de tan sólo dos ediciones) en el que tres parejas de comprometidos que se desconocían entre sí ingresaban a un circuito blindado con cámaras y micrófonos donde se les separaba en 
dos grupos durante tres días a fin de que uno de los cuales interactuara con un individuo, también supuestamente desconocido, pero esta vez del sexo opuesto sobre el cual había de ser desplegada toda una compleja estrategia de engaños, bajo la observación y el sesudo asesoramiento de sus compañeros(as) sentimentales con base en lo que, desde una habitación externa, se les mostraba. Consistía en una dinámica en la que las desesperadas maniobras de convencimiento devenían invariablemente de seducción, lo que terminaba haciendo de los estrategas impotentes voyeurs $y$ del espectador un privilegiado metavoyeur.

Pero prácticamente la totalidad de estos nuevos programas televisivos ambientados en un escenario cada vez más cotidiano, doméstico, promueven una participación del espectador más activa — participación que, cabe dejar constancia, queda reducida a la inducción de llamadas telefónicas-. Esto se traduce, como no podía ser de otra forma, en la conversión del espectador en audiencia, esto es, en consumidor descaradamente directo. Por cierto que una participación más compleja es lo que está a la base de los video-juegos, cuya fenomenología se encuentra en la promisoria integración del espectador a la escena observada, de manera que ahí se realiza su deseo sin más intermediación que la del personaje que lo subroga. Si lo común, en definitiva, de todos estos productos es que construyen sus narrativas para posicionar al espectador como voyeur, que adecuan las innovaciones tecnológicas combinándolas con las formales para una inmersión cada vez más profunda en la escena, el paso definitivo habrá sido dado cuando deje de ser una virtualidad $y$ finalmente pueda llevar a cabo, como Alicia, el salto hacia el otro lado de la pantalla.

En todo caso, se está ante un cambio en el régimen de representación de la imagen, que genera efectos por un lado en la recepción, como un recato en el que mira, porque ahora es la imagen la que, impúdica, se le muestra: es decir, ya no es el espectador el que busca la imagen sino la imagen la que busca al espectador.
Por otro lado, el cambio concierne a una transformación de la representación misma, porque la realidad ${ }^{8}$ ha pasado a cambiar su propia condición de visualidad: se dispone o se predispone la visión pero también la manera de proyectarla, es decir, se determina qué mirar y la manera de hacerlo.

\section{REFERENCIAS BIBLIOGRÁFICAS}

Aumont, Jacques et ál. Estética del cine: espacio fílmico, montaje, narración, lenguaje. Barcelona. Paidós, 1996.

Augé, Marc. Los no lugares: espacios del anonimato. Una antropología de la sobremodernidad. Barcelona. Gedisa, 2000 .

Bentham, Jeremy. El panòptic. Barcelona. Edicions 62, 1985.

Calabrese, Omar. La era neobarroca. Madrid. Cátedra. 1989.

Català Domènech, Josep Maria. "Somnis de la raó tecnològica. A propòsit de Bodies in technology de Don Ihde". Quaderns del CAC 13, maig-agost. 2002: 57-64.

Calvert, Clay. Voyeur Nation: Media, Privacy, and Peering in Modern Culture. Colorado: Westview Press, 2004.

Davis, Flora. La comunicación no verbal. Madrid. Alianza, 1976.

8 Ese proceso cada vez más cotidiano de conversión de algo para ser visto contempla desde los platós de Gran Hermano o el idílico Seaheaven (el pueblo de Truman Burbank, el protagonista de The Truman Show, 1998) hasta los emplazamientos turísticos. 
Denzin, Norman K. The Cinematic Society. The Voyeur's Gaze. London-Thousand OaksNew Delhi. Sage, 1995.

Didi-Huberman, Georges. Lo que vemos, lo que nos mira. Buenos Aires: Manantial, 1997.

Eco, Umberto. La estrategia de la ilusión. Barcelona. Lumen, 1986.

Evans, Jessica and Hall, Stuart. Visual Culture: the Reader. London. Sage, 1999.

Freedberg, David. El poder de las imágenes. Madrid. Cátedra, 1992.

Freud, Sigmund. Introducción al narcisismo y otros ensayos. Madrid. Alianza, 1973a.

Tres ensayos sobre teoría sexual. Madrid. Alianza, 1973b.

Gubern, Roman. Máscaras de la ficción. Barcelona: Anagrama, 2002.

Langer, John. La televisión sensacionalista: el periodismo "popular" y las otras noticias. Barcelona: Paidós, 2000.

Levin, Thomas Y.; Frohne, Ursula and Weibel, Peter (eds.). Ctrl [Space] Rhetorics of Surveillance from Bentham to Big Brother. Karlsruhe. ZKM Center of Art and Media/The MIT Press, 2002.

Mulvey, Laura. Placer visual y cine narrativo. Valencia: Fundación Instituto Shakespeare, 1998.

Orwell, George. Nineteen Eighty-Four. New York: Penguin Books, 1977.

Ramírez, Juan Antonio. Duchamp. El amor y la muerte, incluso. Madrid. Siruela, 2000.
Screen. The Sexual Subject: a Screen Reader in Sexuality. London-New York: Routledge, 1999.

Starobinski, Jean. El ojo vivo. Valladolid: Cuatro, 2002.

Žižek, Slavoj. Mirando al sesgo. Una introducción a Jacques Lacan a través de la cultura popular. Barcelona: Paidós, 2002.

\section{FILMOGRAFÍA CITADA}

Buñuel, Luis. Él. México: Ultramar Films, blanco y negro. $91 \mathrm{~min} .1952$.

Haneke, Michael. Código desconocido (Code inconnu: récit incomplet de divers voyages). Francia-Alemania-Rumanía: Marin Karmitz/Alain Sorde/Yvon Crenn, color. $118 \mathrm{~min} .2000$.

- Escondido (Caché). FranciaAustria-Alemania-Italia: Les Filmes du Losange/Wega Films/Bavaria Film/Bim Distribuzione, color, 117 min. 2005.

. Funny Games (Funny Games). Austria: Wega Films, color, $103 \mathrm{~min}$. 1997.

Hitchcock, Alfred. La ventana indiscreta (Rear Window). Estados Unidos: Paramount, color, 114 min. 1954.

Tsuchiya, Yutaka. Peep "TV" Show (Peep "TV" Show). Japón: W-TV Office, color, $98 \mathrm{~min}$. 2003.

Weir, Peter. El show de Truman (The Truman Show). Estados Unidos: Paramount, color, 103 min. 1998. 